\title{
A new species of Ophtalmibidion Martins from French Guiana, and notes on O. Iuscum Martins (Coleoptera, Cerambycidae, Cerambycinae)
}

\author{
Josef Vlasak ${ }^{1} \&$ Antonio Santos-Silva ${ }^{2}$ \\ ${ }^{1}$ Independent researcher. Schwenksville, PA, U.S.A. ORCID: https://orcid.org/0000-0001-7514-0305. E-mail: josef_vlasak@merck.com \\ ${ }^{2}$ Universidade de São Paulo (USP), Museu de Zoologia (MZUSP). São Paulo, SP, Brasil. ORCID: https://orcid.org/0000-0001-7128-1418. \\ E-mail: toncriss@uol.com.br
}

\begin{abstract}
Ophtalmibidion gutta sp. nov. is described from French Guiana. The elytral color pattern of Ophtalmibidion luscum Martins, 1971 is commented on. A key to species of Ophtalmibidion is provided as well as photographs of all species.
\end{abstract}

Keywords. Neoibidionina; Neoibidionini; South America; Taxonomy.

\section{INTRODUCTION}

Ophtalmibidion was described by Martins (1969) to include Octoplon tetrops Bates, 1870, type species of the genus, and Ophtalmibidion oculatum Martins, 1969. Among the features pointed out in the original description, the most conspicuous are: head strongly narrowed behind the eyes; eyes divided; and procoxal cavities posteriorly open. Later, Martins (1971) described Ophtalmibidion luscum and reported (translated): "The species described below [O. luscum] has the eyes not divided, although the connection between the lobes has a single row of ommatidia. The other features, especially the strongly narrowed aspect of the head and anterior part of the prothorax, justify its inclusion in the genus."

After this, two more species with eye lobes connected by a single row of ommatidia were described: A. auba Martins \& Galileo, 1999; and A. antonkozlovi Santos-Silva, Nascimento \& Drumont, 2019. We believe that the species with the eyes not completely divided need to be transferred to a new genus. However, this is beyond the scope of this work. The new species described here has the eyes distinctly divided.

Currently, the species of Ophtalmibidion are known only from South America (Monné, 2021; Tavakilian \& Chevillotte, 2021).

\section{MATERIAL AND METHODS}

Photographs were taken in the MZSP with a Canon EOS Rebel T3i DSLR camera, Canon MP-E
$65 \mathrm{~mm}$ f/2.8 1-5× macro lens, controlled by Zerene Stacker AutoMontage software. Measurements were taken in "mm" using measuring ocular Hensoldt/Wetzlar - Mess 10 in the Leica MZ6 stereomicroscope, also used in the study of the specimens. The holotype of the new species described here was collected by the first author and was attracted by lights. The type locality lies within the Kaw Mountains of French Guiana. The ecosystem of the area has been described by Morvan \& Morati (2006).

The acronyms used in the text are as follows: AACP - Alain Audureau Collection Private, Saint Gilles Croix de Vie, France; JVCO - Josef Vlasak collection, Schwenksville, Pennsylvania, USA; MZSP - Museu de Zoologia, Universidade de São Paulo, São Paulo, Brazil.

\section{RESULTS}

\section{Ophtalmibidion gutta sp. nov.} (Fig. 1)

Description: Holotype female: Head capsule dark brown, except reddish-brown antennal tubercles; ventral mouthparts reddish brown, with apex of palpomeres yellowish; anteclypeus and labrum brown; scape dark brown, except reddish brown dorsal apex; pedicel reddish brown; antennomeres orangish brown (III slightly darker), except dark brown dorsal and ventral longitudinal carina. Prothorax dark brown, almost black; ventral surface of mesothorax dark brown; ventral surface of metathorax brown, except large 
light orangish-brown macula on each side of posterior region of metaventrite, and dark orangish-brown posterocentral area. Scutellum dark brown on anterocentral area, black on remaining surface. Elytra reddish-brown on narrow basal area, circum-scutellar region, humerus, and sides of basal 1/11; with large $\mathrm{X}$-shaped dark brown macula on basal half (considering both elytra); area on sides of $\mathrm{X}$-shaped band light yellowish-brown; with large dark brown drop-shaped macula on posterior half (considering both elytra), not reaching apex; area between X-shaped and drop-shaped maculae lightly yellowish-brown, and remaining surface gradually pale yellowish-white toward apex. Femora brownish; tibiae brownish basally, orangish-brown on remaining surface; protarsus dark brown; meso- and metatarsus reddish brown. Abdominal ventrites 1-4 brown, with some areas slightly reddish-brown, except dark brown transverse narrow band near apex; ventrite 5 reddish-brown basally, gradually orangish-brown toward apex.

Head: Frons (Fig. 1D) abundantly rugose-punctate, with U-shaped sulcus down to clypeus; with short, decum- bent, very sparse whitish setae, bristly, slightly yellowish close to inferior area of eyes. Area between antennal tubercles rugose-punctate, with sparse, decumbent whitish setae; area between antennal tubercles and upper eye lobes slightly transversely depressed, rugose-punctate, with a few minute, decumbent whitish setae; area from anterior margin of upper eye lobes and middle of area between posterior margin of eyes and prothorax rugose-punctate, and remaining surface of vertex coarsely, sparsely punctate; with sparse, decumbent short whitish setae (almost absent on punctate area), and long erect, sparse yellowish setae interspersed on rugose-punctate area. Area behind upper eye lobes somewhat longitudinally rugose close to eye, sparsely punctate close to prothoracic margin; with minute, sparse, decumbent whitish setae; area between eye lobes almost smooth superiorly, sparsely punctate inferiorly, glabrous; area behind lower eye lobes rugose-punctate superiorly close to eye, finely, sparsely punctate inferiorly close to eye, almost smooth close to prothorax; with long, erect yellowish-brown setae on rugose-punctate area. Area between eye lobes and anten-
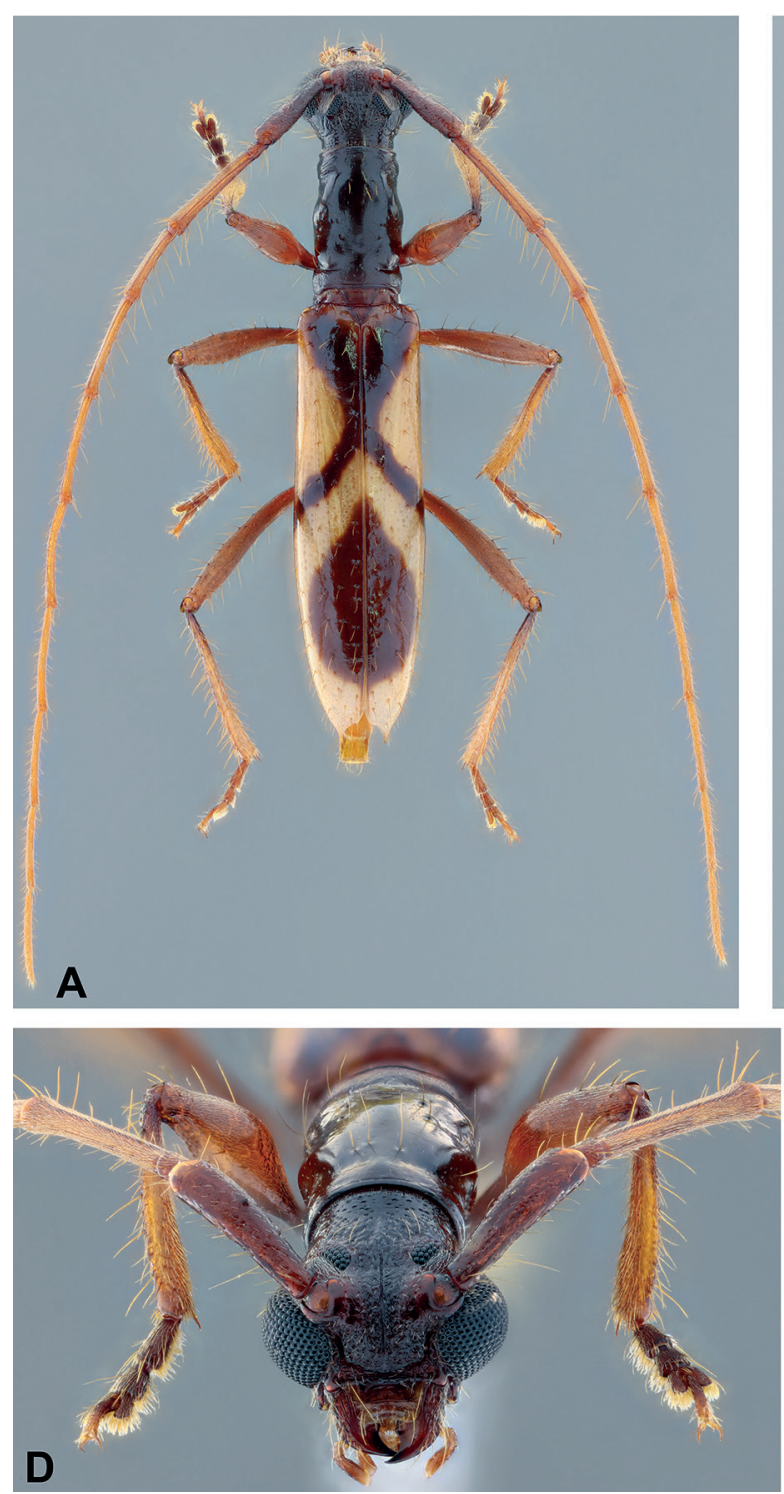
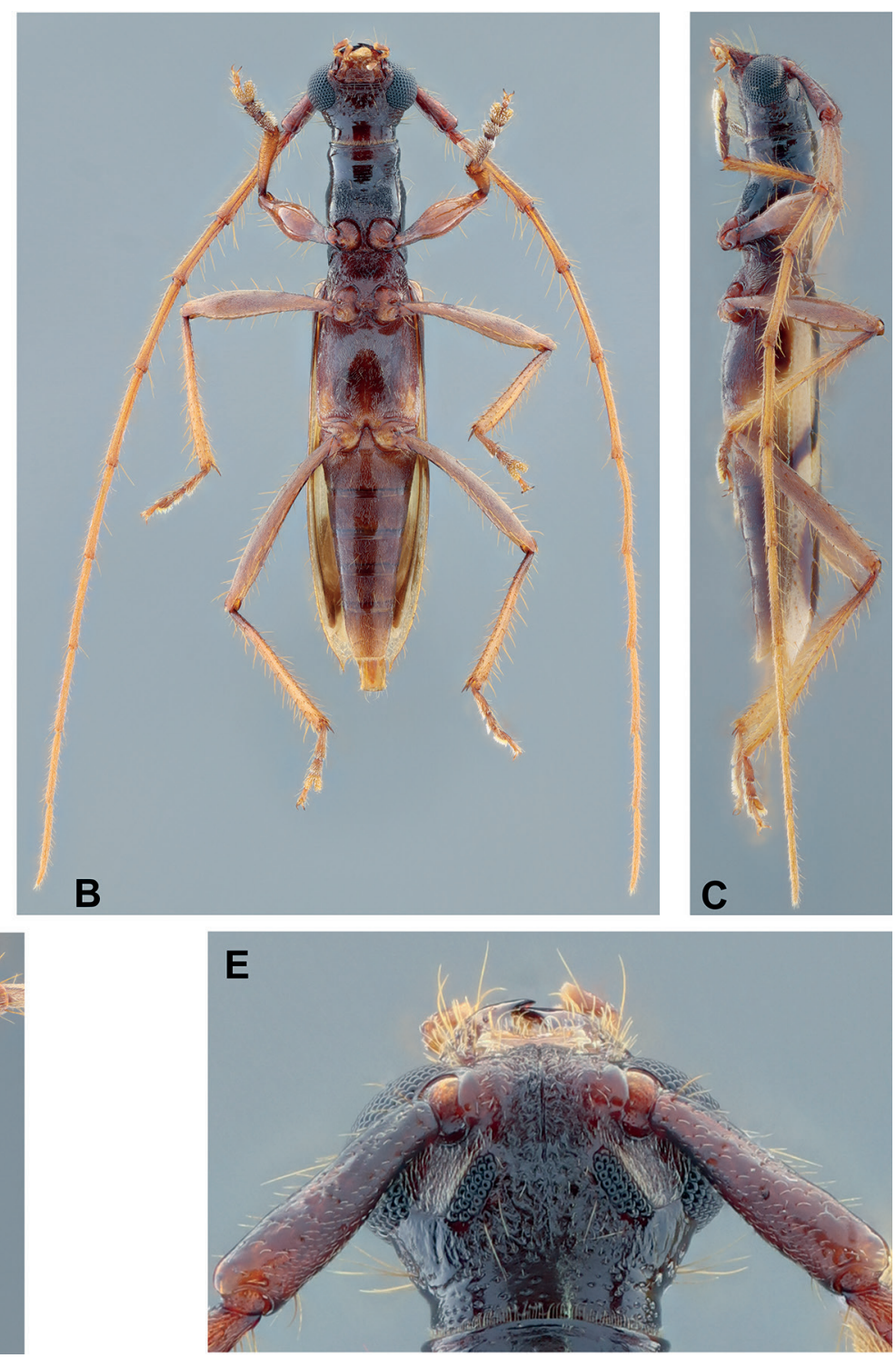

Figure 1. Ophtalmibidion gutta sp. nov., holotype female: (A) Dorsal habitus; (B) Ventral habitus; (C) Lateral habitus; (D) Head, frontal view; (E) Head, dorsal view. 
nal base with dense grayish-white pubescence. Genae with a few moderately long, erect yellowish setae close to eye, glabrous on remaining surface. Antennal tubercles finely, sparsely punctate basally, smooth apically; with a few short, decumbent whitish setae basally, glabrous apically. Median groove well marked from middle of frons to depressed area between antennal tubercles and upper eye lobes. Wide central area of postclypeus rugose-punctate, with short, sparse, bristly whitish setae, and one long, erect yellow seta on each side. Sides of postclypeus smooth, glabrous. Labrum smooth close to anteclypeus, finely punctate anteriorly; glabrous close to anteclypeus, with a few short, bristly whitish setae centrally, long, erect yellowish-brown setae laterally, and moderately short, erect yellowish-brown setae on center of anterior half. Gulamentum smooth, glabrous on posterior third, transversely striate, with both short and long, erect, sparse yellowish setae on anterior area, coarsely, sparsely punctate, with both short and long, erect, sparse yellowish setae on remaining surface. Distance between upper eye lobes 0.24 times distance between outer margins of eyes; in frontal view, distance between lower eye lobes 0.43 times distance between outer margins of eyes. Antennae 2.3 times elytral length, reaching elytral apex near middle of antennomere VIII. Scape slightly widened from base to apex, finely, sparsely punctate except smooth apex; with short, decumbent, sparse yellowish-white setae, more abundant on inner surface, and short, erect, sparse yellowish-brown setae interspersed (erect setae slightly longer near apex of ventral surface). Pedicel with decumbent yellowish pubescence not obscuring integument, and long, erect yellowish-brown setae interspersed dorsally and ventrally. Antennomeres III-V longitudinally carinate dorsally and ventrally; antennomeres with yellowish-white pubescence not obscuring integument; antennomeres III-VI with long, erect yellowish-brown setae ventrally and apex of dorsal surface (setae of ventral surface distinctly longer); antennomeres VII-X with long, erect yellowish-brown setae apically; antennomeres with short, erect, sparse yellowish setae interspersed throughout. Antennal formula based on length of antennomere III: scape $=0.84$; pedicel $=0.15 ; \mathrm{IV}=0.81 ; \mathrm{V}=1.00 ; \mathrm{VI}=1.00 ; \mathrm{VII}=1.00$; $\mathrm{VIII}=0.97 ; \mathrm{IX}=0.90 ; \mathrm{X}=0.78 ; \mathrm{XI}=0.86$.

Thorax: Prothorax about 1.5 times longer than wide; anterior and posterior constrictions well marked; sides sinuous, with slight central gibbosity. Pronotum minutely, very sparsely punctate; with narrow transverse sulcus close to anterior and posterior margins; anterior fifth somewhat obliquely striate laterally; anterior margin convex, and posterior margin concave; with moderately wide sulcus laterally on area of constrictions; with minute whitish setae emerging from nearly all punctures and a few long, erect yellowish-brown setae on center of dorsal third and sides of posterior $2 / 3$. Sides of prothorax minutely, very sparsely punctate, except posterior area somewhat rugose. Prosternum with grayish-white pubescence on posterior half, pubescence slightly spars- er centrally and absent close to sides of prothorax; anterior half almost glabrous. Narrowest area of prosternal process 0.15 times procoxal width. Ventral surface of mesothorax with abundant grayish-white pubescence laterally, slightly sparser on anterocentral area of mesoventrite, almost absent on posterocentral area of mesoventrite and base of mesoventral process. Ventral surface of metathorax with abundant yellowish-white pubescence not obscuring integument, distinctly sparser on posterocentral $2 / 3$ of metaventrite (absent on center of this region); with a few long, erect yellowish setae on metaventrite. Scutellum with abundant yellowish pubescence not obscuring integument. Elytra: With somewhat coarse, very sparse punctures, from each emerges long, erect yellowish-brown seta (erect setae more brownish basally); apex obliquely truncate (slightly concave), with long spine on outer angle. Legs: Femora with abundant, minute yellowish-white pubescence not obscuring integument, and long, erect yellowish-brown setae interspersed (part of erect setae brownish basally or entirely brownish, especially dorsally). Tibiae with moderately abundant, erect yellowish-brown setae, distinctly denser on ventral surface of protibiae. Metatarsomere I as long as II-III together.

Abdomen: Ventrites with abundant yellowish-white pubescence not obscuring integument, except glabrous apex of ventrites 1-4, and long, erect, sparse yellowish-brown setae interspersed. Apex of ventrite 5 truncate.

Male: It differs from female by the longer antennae, 2.8 times elytral length, reaching elytral apex about middle of antennomere VII.

Dimensions (mm) (holotype female): Total length, 8.95; prothoracic length, 1.80; anterior prothoracic width, 1.05; posterior prothoracic width (maximum prothoracic width), 1.15; humeral width, 1.55; elytral length, 5.65.

Type material: Holotype female from FRENCH GUIANA: Camp Caimans, Kaw Mt., at lights, 26.VIII-07.IX.2019, J. Vlasak leg. (MZSP, formerly JVCO). Paratype male from FRENCH GUIANA: Kaw road, PK37 (light trap), 15.09.1998, Alain Audureau leg. (AACP).

Etymology: The name gutta (Latin, meaning a drop) refers to the dark, drop-shaped macula on the posterior half of the elytra. It is a noun in apposition.

Remarks: Ophtalmibidion gutta sp. nov. is similar to O. oculatum Martins, 1969, but differs as follows: Each elytron with dark brown C-shaped band on basal half (X-shaped considering both elytra); macula on posterior half of the elytra dark brown and not reaching lateral margins; scape slender and about as long as basal width of the prothorax (Fig. 1A). In O. oculatum, each elytron has a reddish-brown J-shaped band on basal half, macula on posterior half of the elytra reddish-brown and reaching sides, and the scape is stouter and shorter than basal width of the prothorax (Fig. 2A). 


\section{Ophtalmibidion luscum Martins, 1971}

(Fig. 2E)

Ophtalmibidion luscum Martins, 1971: 1449; Monné, 1993:39 (cat.); Monné \& Giesbert, 1994: 76 (checklist); Monné, 2005: 357 (cat.); Monné \& Hovore, 2006: 94 (checklist); Martins \& Galileo, 2007: 203; Monné et al., 2017: 5 (distr.); Santos-Silva et al., 2019: 6 (key); Monné, 2021: 516 (cat.).
Remarks: According to Martins (1971) (translated): "Elytra orangish; each with a whitish, well-developed, slightly oblique downward macula, from margin to the suture in the middle of the anterior half, and a whitish reverse oblique band in the middle. Macula and band bordered by slightly darker color." Looking at the photograph in Martins (1971), the description of the whitish areas of the elytra seems to agree very well. Martins \& Galileo (2007)
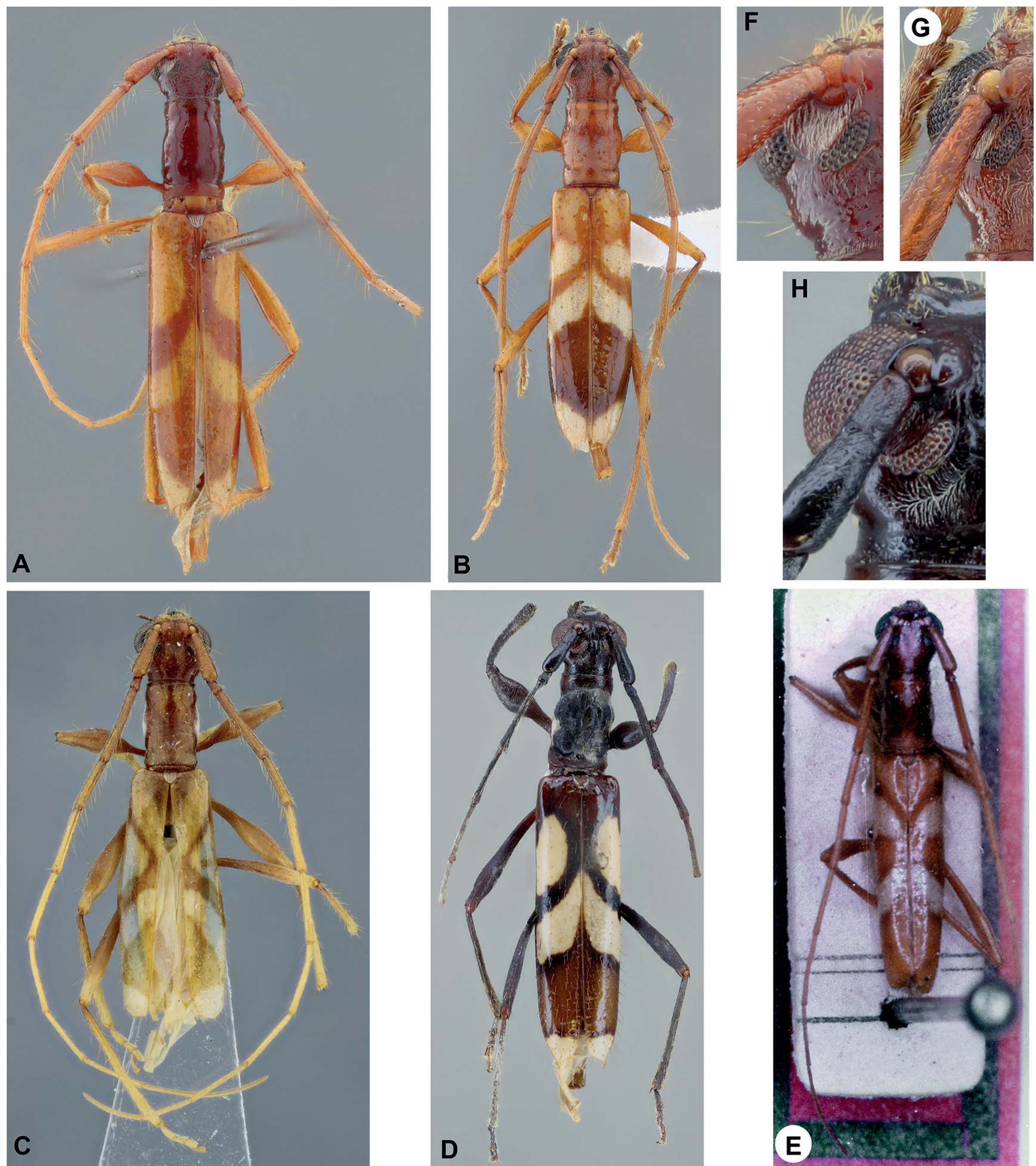

Figure 2. Ophtalmibidion sp. (A-E) Dorsal habitus: (A) 0. oculatum Martins, 1969, holotype female; (B) 0. tetrops (Bates, 1870), female from Bolivia; (C) 0. auba Martins \& Galileo, 1999, holotype male; (D) 0. antonkozlovi Santos-Silva, Nascimento \& Drumont, 2019, holotype male; (E) 0. Iuscum Martins, 1971, holotype male. (F-H) Eyes: (F) 0. oculatum, holotype female; (G) 0. tetrops, female from Bolivia; (H) 0. antonkozlovi, holotype male. 
repeated the original description of the color of the elytra, but provided a different photo of the holotype, taken from a slightly different angle, that appears to contradict the original description and the redescription. This is the same photograph provided here (Fig. 2E) (taken by Karl Ernst Hüdepohl, Germany). The elytra appear not to have two isolated whitish maculae, but a single and large C-shaped band centrally (X-shaped considering both elytra). It is possible that this whitish area between the two oblique areas is just light reflection. It will be necessary to examine the holotype or get better photographs to be sure. Martins \& Galileo (2007) also listed a second specimen of O. luscum: "BRASIL, Espírito Santo: Linhares, female, XI.1972, P.C. Elias col. (MZSP)." However, this specimen is O. oculatum, practically identical to the holotype, and it is correctly identified in the MZSP collection.

\section{Key to species of Ophtalmibidion}

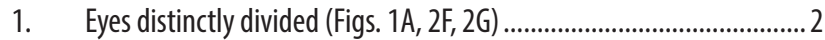

- Eyes not divided, with a single row of ommatidia between upper and lower eye lobes (Fig. 2H)

2(1). Pronotum with distinct pubescence; elytra with oblique yellowish band before middle (Fig. 2B). Peru, Bolivia, Brazil (Pará, Goiás, Mato Grosso, Mato Grosso do Sul, Minas Gerais, São Paulo, Paraná), Bolivia (Santa Cruz), Argentina (Misiones), Paraguay ..0. tetrops (Bates, 1870)

- Pronotum without pubescence; elytra without oblique yellowish or whitish band before middle.

3(2). Each elytron with reddish-brown J-shaped band on basal half; macula on posterior half of elytra reddish-brown, reaching sides; head and prothorax reddish-brown; scape stouter and shorter than basal width of prothorax (Fig. 2A). Brazil (Espírito Santo)

0. oculatum Martins, 1969

- Each elytron with dark brown C-shaped band on basal half (X-shaped considering both elytra); macula on posterior half of elytra dark brown, not reaching sides; head black and prothorax dark brown; scape slender and about as long as basal width of prothorax (Fig. 1). French Guiana O. gutta sp. nov.

4(1). Elytra with oblique whitish band on basal half downward from margin to the suture (Fig. 2E). Brazil (Mato Grosso do Sul, Espírito Santo) ....... .0. Iuscum Martins, 1971

- Elytra without oblique whitish band on basal half downward from margin to suture

5(4). Antennae and legs orangish-brown; head capsule and prothorax brown; elytral apex without long spine at outer angle (Fig. 2C). Brazil (Amazonas). 0. auba Martins \& Galileo, 1999

- Antennae and legs black; head capsule and prothorax black; elytral apex with long spine at outer angle (Fig. 2D). Colombia (La Guajira) ... 0. antonkozlovi Santos-Silva, Nascimento \& Drumont, 2019

AUTHORS' CONTRIBUTIONS: JV, AS-S: Conceptualization, Methodology, Writing - review \& editing; AS-S: Investigation, Writing - original draft. All authors actively participated in the discussion of the results, they reviewed and approved the final version of the paper.
CONFLICTS OF INTEREST: Authors declare there are no conflicts of interest.

FUNDING INFORMATION: This project did not use any external financial support.

ACKNOWLEDGMENTS: We express our thanks to Rafael Souza (MZSP) for digitizing the slide of the holotype of Ophtalmibidion luscum. We would also like to thank Alain Audureau, Jean-Louis Giuglaris, Jean-Philippe Roguet, Larry Bezark, Odette Morvan, Pierre-Henri Dalens, Roy Morris, and Steve Lingafelter for help searching for additional specimens of Ophtalmibidion gutta in their collections.

\section{REFERENCES}

Martins, U.R. 1969. Monografia da tribo Ibidionini (Coleoptera, Cerambycinae). Parte III. Arquivos de Zoologia, 16(3): 631-877. https://doi.org/10.11606/ issn.2176-7793.v16i3p631-877.

Martins, U.R. 1971. Monografia da tribo Ibidionini (Coleoptera, (erambycinae). ParteVI. Arquivos de Zoologia, 16(6): 1343-1508. https:// doi.org/10.11606/issn.2176-7793.v16i6p1343-1508.

Martins, U.R. \& Galileo, M.H.M. 2007. Tribo Ibidionini, Subtribo Ibidionina. In: Martins, U.R. (Org.). Cerambycidae sul-americanos (Coleoptera) Taxonomia. Volume 9. Curitiba, Sociedade Brasileira de Entomologia. p. $177-330$.

Monné, M.A. 1993. Catalogue of the Cerambycidae (Coleoptera) of the Western Hemisphere. Part V. Subfamily Cerambycinae: Tribe Ibidionini. São Paulo, Sociedade Brasileira de Entomologia. 100p.

Monné, M.A. 2005. Catalogue of the Cerambycidae (Coleoptera) of the Neotropical Region. Part I. Subfamily Cerambycinae. Zootaxa, 946: 1-765.

Monné, M.A. 2021. Catalogue of the Cerambycidae (Coleoptera) of the Neotropical region. Part I. Subfamily Cerambycinae. Available: https:// cerambycids.com/catalog. Access: 27/08/2021.

Monné, M.A. \& Giesbert, E.F. 1994. Checklist of the Cerambycidae and Disteniidae (Coleoptera) of the Western Hemisphere. Wolfsgarden Books, Burbank, 409p.

Monné, M.A. \& Hovore, F.T. 2006. A Checklist of the Cerambycidae, or longhorned wood-boring beetles, of the Western Hemisphere. Rancho Dominguez, Bio Quip Publications. 393p.

Monné, M.A.; Santos-Silva, A., Casari, S.A. \& Monné, M.L. 2017. Checklist of Cerambycidae, Disteniidae and Vesperidae (Coleoptera) primary types of the Museu de Zoologia, Universidade de São Paulo, São Paulo, Brazil. Zootaxa, 4249(1): 1-104. https://doi.org/10.11646/zootaxa.4249.1.1.

Morvan, 0. \& Morati, J. 2006. Contribution a la connaisance des Cerambycidae de la montagne de Kaw, Guyane Française (Coleoptera). Lambillionea, 106(3), suppl. 2:3-62.

Santos-Silva, A.; Nascimento, F.E.L.; Drumont, A. \& Kozlov, A.0. 2019. Descriptions, notes and new records in South American Cerambycidae (Coleoptera). Papéis Avulsos de Zoologia, 59(15):1-13, e20195915. https://doi.org/10.11606/1807-0205/2019.59.15.

Tavakilian, G.L. \& Chevillotte, H. 2021. Titan: base de données internationales sur les Cerambycidae ou Longicornes. Available: http://titan.gbif.fr. Access: 27/08/2021. 